\title{
The effect of ethanolic extract of propolis and glucose oxidase on secondary infections of cutaneous leishmaniasis
}

\author{
Kahin Shahani Poor ${ }^{1}$, Shakiba Firoozi ${ }^{2 *}$, Monir Doudi ${ }^{2}$, Nafiseh Sadat Naghavi ${ }^{2}$ \\ and Mahbubeh Setorki ${ }^{3}$ \\ ${ }^{1}$ Department of Biochemistry, Falavarjan Branch, Islamic Azad University, Falavarjan, Iran. \\ ${ }^{2}$ Department of Microbiology, Falavarjan Branch, Islamic Azad University, Falavarjan, Iran. \\ 3Department of Biology, Izeh Branch, Islamic Azad University, Izeh, Iran.
}

Accepted 2 August, 2012

\begin{abstract}
Leishmaniasis is an endemic parasitosis that leads to chronic cutaneous lesions. These lesions may be infected by bacteria and lead to secondary infections. Propolis is a wax-like resin produced by honeybees from substances collected from plants, which are mixed with beeswax and other compounds of bee metabolism. Propolis is a mixture of balsams and resins, waxes, essential oils, phenólicos, pollen, and other substances that is used by bees in the construction, repair and protection of their hives, mainly due to its mechanical properties and antimicrobial activity. Glucose oxidase (GOX) is a type of enzyme commonly found in many types of fungus and bacteria. Glucose oxidase plays a key role not only in digestive processes, but also, and perhaps more importantly, in overall human health, physical rejuvenation and antibacterial activity. Glucose oxidase catalyzes the oxidation of $\beta$-D-glucose to D-glucono-1,5-lactone and hydrogen peroxide. The present study was aimed at investigating the susceptibility of the microorganisms Pseudomonas aeruginosa, Escherichia coli, Staphylococcus epidermidis, and Corynebacterium xerosis to ethanolic extracts of propolis (EEP) and glucose oxidase. These bacteria were obtained from secondary infections of cutaneous leishmaniasis. When these bacteria were exposed in vitro to EEP, larger inhibition zones were observed for the Grampositive bacteria, while both Gram-negative and Gram-positive bacteria were sensitive to glucose oxidase.
\end{abstract}

Key words: Cutaneous leishmaniasis, propolis, glucose oxidase.

\section{INTRODUCTION}

Leishmania is an intracellular tissue parasite belonging to the order Kinetoplastida and the family Trypanosomatidae. Different Leishmania species lead to distinct clinical manifestations known as visceral, cutaneous and mucocutaneous leishmaniasis (Pearson et al., 1999). The disease, caused by several species of the protozoan is currently endemic in 88 countries. Some 12 million people are infected and the population at risk is 350 million. Injected into mammalian hosts by phlebotomus sand flies as extracellular promastigotes,

\footnotetext{
*Corresponding author. E-mail: shfiroozib@gmail.com.
}

Leishmania bind to macrophages and are quickly phagocytosed. All Leishmania species are obligatorily intracellular parasites that live within secondary phagolysosomes. In this way, the parasite is able to multiply, lyse the host cell, and infect surrounding macrophages (Solbach and Laskay, 2000). The severity of the disease varies as it passes from cutaneous or mucosal to visceral or diffuse cutaneous infection (Grimaldi and Tesh, 1993; Murray et al., 2005). The first is generally caused by Leishmania amazonensis, a species transmitted mainly in the Amazon region, which is associated with localized cutaneous lesions (Grimaldi and Tesh, 1993).

Chemotherapy remains the mainstay for the control of 
leishmaniasis, as effective vaccines have yet to be developed (Murray et al., 2005). The first line of therapy for all forms of the disease requires potentially toxic and painful multiple injections of pentavalent antimonials (Berman, 2003). The problem is further aggravated by the appearance of resistance to these drugs in some endemic areas. Many studies have been conducted to find an effective therapy for leishmaniasis and its secondary infections that avoids exposure to potentially toxic drugs, including screening of plant extracts and plant-derived compounds (Abreu et al., 1999; Carvalho and Ferreira, 2001; Rocha et al., 2005). The bacterial flora from leishmanial ulcers was studied. The aerobic species Staphylococcus aureus and Pseudomonas aeruginosa were found most frequently. Evaluation of the sensitivity of these species to antibiotics showed that $100 \%$ of these isolates of $S$. aureus were sensitive to vancomycin, amikacin and chloramphenicol, while $100 \%$ of the isolates of $P$. aeruginosa were sensitive to amikacin, gentamicin and tobramycin. These species were generally resistant to penicillin and tetracycline (Gonçalves et al., 2009).

Propolis is a resinous substance that honey bees collect from different plant exsudates (Marcucci 2000). Propolis is claimed to posses versatile valuable pharmacological activities and has, to date, been taken in internal and external dosage forms for the treatments of various diseases (Burdock, 1998; Marcucci and Bankova, 1999; Marcucci, 1995). It is widely used in products like "healthy foods" and "biocosmetics". Many authors have reported the in vitro activities of propolis against different microorganisms; among them are some important human pathogens, such as S. aureus, Salmonella typhimurium, Candida albicans, Trypanosoma cruzi, and Giardia duodenalis (Higashi and de Castro, 1994; Marcucci et al., 2001; Miorin et al., 2003; Uzel et al., 2005; Dantas et al., 2006; Freitas et al., 2006; Trusheva et al., 2006; Ayres et al., 2006). Most of the antibacterial, antifungal and antiinflammatory activity of propolis is due to the presence of polar compounds, mainly phenols (flavonoids, phenolic acids and their esters) and aromatic acids (caffeic acid and p-coumaric acid) (Gonsales et al., 2006; Krol et al., 1996).

Glucose oxidase is a type of enzyme commonly found in many fungi and bacteria and it is often extracted from Aspergillus niger (Clarke et al., 2006). The $\mathrm{pH}$ optimum for glucose oxidase is 5.5 , while it has a broad activity range of $\mathrm{pH} 4-7$. Glucose oxidase is specific for $\beta$-Dglucose with a KM of 33-110 mM. Glucose oxidase from $A$. niger is a dimer consisting of 2 equal subunits each, with a molecular weight of $80 \mathrm{kDa}$. Each subunit contains one mole of flavin adenine dinucleotide and one mole of iron. The enzyme is a glycoprotein containing approximately $16 \%$ neutral sugar and $2 \%$ amino sugar (Tsuge et al., 1975).

Glucose oxidase (GOX) is of interest in relation to the antibacterial properties of honey (Cooper and Molan,
1999; Molan, 1992). It catalyses glucose to form gluconic acid and hydrogen peroxide $\left(\mathrm{H}_{2} \mathrm{O}_{2}\right)$ - the main agent responsible for antibacterial activity in most honeys (Ceksteryte, 2000; Subers and Schepartz, 1963). The antibacterial effect of the glucose oxidase-glucose system was studied on food-poisoning organisms, including S. aureus, Salmonella infantis, Clostridium perfringens, Bacillus cereus, Campylobacter jejuni, Listeria monocytogenes and Yersinia enterocolitica, using automated turbidometry (Tiina and Sandholm, 1989).

Since propolis and glucose oxidase, both are the products of bee, they were used in this study (glucose oxidase found in honey). This report describes in vitro analyses of the effects of ethanolic extracts of propolis and glucose oxidase on both Gram-positive and Gramnegative bacteria from secondary infections of cutaneous leishmaniasis sores.

\section{MATERIALS AND METHODS}

Propolis samples were ground to powder and subjected to extraction with $70 \%$ ethanol. Then the ethanolic extracts of propolis (EEP) was diluted with $5 \%$ dimethyl sulfoxide (DMSO) to produce various dilutions of EEP. In brief, $1.0 \mathrm{ml}$ ethanolic extract of propolis was dissolved by $1.0 \mathrm{ml} 5 \%$ DMSO to obtain the dilution of $1 / 2$ and was continued to dilution of $1 / 4,1 / 8$, etc (Kujumgiev et al., 1999).

The glucose oxidase enzyme (EC. 1.1.3.4) is an oxido-reductase that catalyses the oxidation of glucose to hydrogen peroxide and Dglucono- $\delta$-lactone. It is often extracted from $A$. niger (Hartnett et al., 1999). The used enzyme solution was $10 \mathrm{kU} / \mathrm{L}$ activity. Then $1.0 \mathrm{ml}$ of the enzyme was dissolved by $1.0 \mathrm{ml}$ water to obtain the dilution of $1 / 2$ and was continued to dilution of $1 / 4,1 / 8$, etc.

\section{Isolation and identification of bacterial strains}

Bacterial strains isolates were recovered from patients with cutaneous leishmaniasis attended to in the Department of Research in Skin and Cutaneous Leishmaniasis, Isfahan, Iran. Swabs were taken from patient using sterile cotton swabs. Then, the samples were cultured on nutrient agar and incubated at $37^{\circ} \mathrm{C}$. The identification of the bacterial isolates was confirmed using conventional biochemical tests. Four bacteria strains were obtained from the infections of wounds of cutaneous leishmaniasis.

\section{Antibacterial activity tests}

The agar disk diffusion method was employed to test the antimicrobial activity of EEP and glucose oxidase (Kujumgiev et al., 1999; Sforcin et al., 2000). Inoculum was prepared using fresh cultures of bacteria strains cultured on nutrient agar. A loop full of bacterial culture was inoculated into a nutrient broth medium and incubated for $24 \mathrm{~h}$ at $37^{\circ} \mathrm{C}$. The size was adjusted to $0.5 \mathrm{McF}$ arland standard turbidity, approximately 10 colony-forming units (CFU/ml). Cell suspensions (100 $\mathrm{ml}$ of target strain) were introduced into the nutrient agar plates and spread thinly on the plates using a glass spreader. Furthermore, disks of $6 \mathrm{~mm}$ diameter were impregnated with $20 \mu \mathrm{L}$ of each dilution of EEP and with $70 \%$ ethanol (control), and were impregnated separately with $20 \mu \mathrm{L}$ of each dilution of enzyme. The disks were then placed on inoculated agar plates, which were incubated at $37^{\circ} \mathrm{C}$ for $24 \mathrm{~h}$ under aerobic conditions. The diameter of the inhibition zones (in millimeters) around the disks was measured after $24 \mathrm{~h}$. Tests were performed in duplicate. 
Table 1. The effect of dilutions of EEP on bacteria.

\begin{tabular}{|c|c|c|c|c|c|c|c|c|c|c|c|c|c|c|c|c|}
\hline \multirow{3}{*}{$\begin{array}{l}\text { Bacteria } \\
\text { Dilutions }\end{array}$} & \multicolumn{8}{|c|}{ Gram-negative } & \multicolumn{8}{|c|}{ Gram-positive } \\
\hline & \multicolumn{4}{|c|}{ P. aeruginosa } & \multicolumn{4}{|c|}{ E. coli } & \multicolumn{4}{|c|}{ C. xerosis } & \multicolumn{4}{|c|}{ S. epidermidis } \\
\hline & 1 & $1 / 2$ & $1 / 4$ & $1 / 8$ & 1 & $1 / 2$ & $1 / 4$ & $1 / 8$ & $1 / 8$ & $1 / 16$ & $1 / 32$ & $1 / 64$ & $1 / 8$ & $1 / 16$ & $1 / 32$ & $1 / 64$ \\
\hline $\mathrm{ZOI}(\mathrm{mm})$ & 0 & 0 & 0 & 0 & 0 & 0 & 0 & 0 & 9 & 8 & 0 & 0 & 9 & 8 & 0 & 0 \\
\hline
\end{tabular}

*ZOI: Zone of inhibition.

Table 2. The effect of dilutions of glucose oxidase on bacteria.

\begin{tabular}{|c|c|c|c|c|c|c|c|c|c|c|c|c|c|c|c|c|}
\hline \multirow{3}{*}{$\frac{\text { Bacteria }}{\text { Dilutions }}$} & \multicolumn{8}{|c|}{ Gram-negative } & \multicolumn{8}{|c|}{ Gram-positive } \\
\hline & \multicolumn{4}{|c|}{ P. aeruginosa } & \multicolumn{4}{|c|}{ E. coli } & \multicolumn{4}{|c|}{ C. xerosis } & \multicolumn{4}{|c|}{ S. epidermidis } \\
\hline & $1 / 32$ & $1 / 64$ & $1 / 128$ & $1 / 256$ & $1 / 32$ & $1 / 64$ & $1 / 128$ & $1 / 256$ & $1 / 32$ & $1 / 64$ & $1 / 128$ & $1 / 256$ & $1 / 32$ & $1 / 64$ & $1 / 128$ & $1 / 256$ \\
\hline $\mathrm{ZOI}^{*}(\mathrm{~mm})$ & 15 & 12 & 9 & 0 & 9 & 0 & 0 & 0 & 16 & 14 & 13 & 0 & 15 & 13 & 10 & 0 \\
\hline
\end{tabular}

*ZOI: Zone of inhibition.

\section{RESULTS AND DISCUSSION}

The experiments were undertaken to study a possible effect of propolis and glucose oxidase on secondary infections of cutaneous leishmaniasis. Data from numerous studies concerning antibacterial properties of propolis support the fact that propolis is active mainly against Gram-positive bacteria and either displays much lower activity against the Gram-negative ones or is inactive at all (Sforcin et al., 2000). Results obtained herein also indicated that the inhibitory effects of EEP were not similar between the Gram-negative and the Gram-positive bacteria strains. It seems that Gram negative bacteria are resistance to EEP because there is not any zone of inhibition in their culture (Table 1).

Meanwhile, there are conflicting data on the susceptibility of $E$. coli and $P$. aeruginosa to EEP. But in both of Gram-positive bacteria from the dilution of 1/16 $(1 / 16,1 / 8,1 / 4$, etc) the inhibition zones appeared (Table 1). Such results can be seen in the work of Kujumgiev et al. (1999) who tested propolis samples from different geographic regions (tropical and temperate zones) against $S$. aureus and E. coli. Our results also showed that both Gram-negative and Gram-positive bacteria were sensitive to glucose oxidase, with different sensitivities in different dilutions. Among the bacteria tested, E. coli was the least sensitive (Table 2).

\section{Conclusion}

The present results with EEP, allow the conclusion that Gram-positive bacteria (C. xerosis and S. epidermidis) are more susceptible than Gram-negative bacteria (E. coli and $P$. aeruginosa). These Gram-negative bacteria showing resistance to EEP had no inhibition zones with the various dilutions of EEP, but the Gram-positive bacteria (C. xerosis and $S$. epidermidis) exhibited inhibition zones from dilution of $1 / 16$, where a minimal inhibition zone is seen. Therefore, the ethanolic extract of propolis is a very effective agent for reducing the Grampositive bacteria (C. xerosis and $S$. epidermidis) in secondary infections of leishmaniasis sores. On the other hand, glucose oxidase also showed inhibitory activity against both Gram-positive and Gram-negative bacteria, and could be used for the treatment of the secondary infections of leishmaniasis sores. Moreover, glucose oxidase was effective against bacteria in low dilutions. Thus, the results from this study indicate that glucose oxidase is more effective than propolis for the treatment of secondary infections of the wounds of leishmaniasis.

\section{REFERENCES}

Abreu PM, Martins ES, Kayser O, Binseil KU, Siems K, SeemannA, Brevet J (1999). Antimicrobial, anitumor and antileismanial screening of medicinal plants from Guinea-Bissau. Phytomedicine 6:187-195.

Ayres DC, Marcucci MC, Giorgio S (2006). Treatment methods of leishmaniasis with Brazilian propolis. Requested patent. Brazilian National Institute for Intellectual Property INPI no, PI018060007317.

Berman JD (2003). Current treatment approaches to leishmaniasis. Curr. Opin. Infect. Dis. 16:397-401.

Burdock GA (1998). Review of the biological properties and toxicity of bee propolis (propolis). Food Chem. Toxicol. 36:347-363.

Carvalho PB, Ferreira El (2001). Leishmaniasis phytotherapy Nature's leadership against an ancient disease. Rev. Fitoterapia 72:599-618.

Ceksteryte V (2000). Effect of temperature and storage time on hydrogen peroxide content in honey of different biological origin. Biologija 2:296-298.

Clarke KG, Johnstone M, Price B, Harrison ST (2006). Location of glucose oxidase during production by Aspergillus niger. Appl. Microbiol. Biotechnol. 70:72.

Cooper RA, Molan PC (1999). The use of honey as an antiseptic in managing Pseudomonas infection. Wound Carea 8:161-164.

Gonçalves EG, Reis FSA, Oliveira EG, Pareira AL, Silva AR, Costa JM (2009). Bacterial infection in cutaneous leishmaniasis: Bacterial pattern and sensitivity to antibiotics. Rev. Soc. Bras. Med. Trop. 42(2):219-221

Gonsales GZ, Orsi RO, Fernandes JRA, Rodrigues P, Funari SRC (2006). Antibacterial activity of propolis collected in different regions of Brazil. J. Venom. Anim. Toxins Incl. Trop. Dis. 12:276-284.

Grimaldi GJ, Tesh RB (1993). Leishmaniasis of the new world: Current concepts and implications for future research. Clin. Microbiol. Rev. 
6:230-250.

Hartnett AM, Ingersoll CM, Baker GA, Bright FV (1999). Kinetics and thermodynamics of free flavins and the flavin-based redox active site within glucose oxidase dissolved in solution or sequestered within a solgel-derived glass. Anal. Chem. 71:1215-1224.

Higashi KO, de Castro SL (1994). Propolis extracts are effective against Trypanosoma cruzi and have an impact on its interaction with host cells. Ethnopharmacology 43:149-155.

Krol W, Scheller S, Czuba Z, Matsuno T, Zydowicz G, Shani J, Mos M (1996). Inhibition of neutrophils chemiluminescence by ethanol extract of propolis (EEP) and its phenolic components. J. Ethnopharmacol, 55:19-25.

Kujumgiev A, Tsvetkovai I, Serkedjieva Y, Bankova V, Christov R, Popov S (1999). Antibacterial, antifungal and antiviral activity of propolis of different geographic origin. J. Ethnopharmacol. 64:235-40.

Marcucci MC (1995). Propolis: Chemical composition, biological properties and therapeutic activity. Apidologie 26:517-518.

Marcucci MC (2000). Process to typing natural products. Requested patent. Brazilian National Institute for Intellectual Property INPI no,PI 0105471-6, 12/22/2000.

Marcucci MC, Bankova V (1999). Chemical composition, plant origin and biological activity of Brazilian propolis. Phytochemistry 2:115123.

Marcucci MC, Ferreres F, Garcia-Vigueira C, Bankova Castro SL, Dantas AP, Valente PHM, Paulino N (2001). Phenolic compounds from Brazilian propolis with pharmacological activities. Ethnopharmacology 74:105-112.

Miorin PL, Levy Junior NC, Custodio AR, Bretz WA, Marcucci MC (2003). Antibacterial activity of honey and propolis from Apis mellifera and Tetragonisca angustula against Staphylococcus aureus. Appl. Microbiol, 95:913-920.

Molan PC (1992). The antibacterial activity of honey: 1 . The nature of the antibacterial activity. Bee. World 73:5-28.

Murray HW, Berman JD, Davies CR, Saravia NG (2005). Advances in leishmaniasis. Lancet 366:1561-1577.
Pearson RD, Lereau SM, Georonimo SM (1999). Leishmaniasis at the end of the millennium. Curr. Infect. Dis. Rep. 1:448-452.

Sforcin JM, Fernandes Jr A, Lopes CAM, Bankova V, Funari SRC (2000). Seasonal effect on Brazilian propolis antibacterial activity. J. Ethnopharmacol. 73:243-249.

Solbach W, Laskay T (2000). The host response to Leishmania infection. Adv. Immunol. 74:275-317.

Subers MH, Schepartz Al (1963). The identification of inhibine, the antibacterial factor in honey, as hydrogen peroxide and its origin in a honey glucose-oxidase system. Biochim. Biophys. Acta 73: 57-70.

Tiina M, Sandholm M (1989). Antibacterial effect of the glucose oxidase-glucose system on food-poisoning organisms. Int. J. Food. Microbiol. 8(2):165-174.

Trusheva B, Popova M, Bankova V, Simova S, Marcucci MC, Miorin PL, Pasin FR, Tsvetkova I (2006). Bioactive constituents of Brazilian red propolis. Evid. Based Complement. Alternat. Med. 3:249-254.

Tsuge HJ, Natsuaki O, Ohashi K (1975). Purification, properties, and molecular features of glucose oxidase from Aspergillus niger. J. Biochem. 78: 835-843.

Uzel A, Sorkun K, Oncag O, Cogulu D, Gencay O, Salih B (2005). Chemical compositions and antimicrobial activities of four different Anatolian propolis samples. Microbiol. Res. 160:189-195. 